\title{
Difficulties Faced by Children with Selective Mutism in Schools and Support Thereof
}

\author{
Hiroyuki Matsushita $^{1, *}$, Maiko Okumura ${ }^{2}$, Takanobu Sakai ${ }^{3}$, \\ Mae SHImoyama $^{2}$ and Shigeki Sonoyama ${ }^{4, \dagger}$ \\ ${ }^{1}$ Faculty of Education, Graduate Faculty of Interdisciplinary Research, University of Yamanashi, Japan
${ }^{2}$ Institute of Education, Academic Assembly, Shinshu University, Japan
${ }^{3}$ Faculty of Human Sciences, Konan Women's University, Japan
${ }^{4}$ Faculty of Humanities and Education, The University of Shimane, Japan
}

Previous studies have not fully identified the areas in which children with selective mutism face difficulties in school and the support they are given. A survey was conducted in this study among teachers serving at different tiers of education (kindergarten, elementary, and lower secondary school) to ascertain the teachers' views on the extent of the difficulties children with selective mutism face in-school activities, and their views on the in-school support the children require. What the difficulties faced by children with selective mutism generally have in common is that they occur during activities and in settings requiring speech based on the results of this study. However, individual differences are also shown, particularly in elementary and lower secondary schools. Indications are that support systems involving coordination inside and outside of schools are required and are presently inadequate. Better systems will be required in the future, including the use of special needs education coordinators and the assignment of experts with high levels of expertise. In addition, encouraging understanding among classmates is an effective step despite the difficulties involved, and the development of such programs should be sought. These show that support is required to provide places where children with selective mutism can feel comfortable.

Key Words: selective mutism, school, difficulties, support system

\section{Introduction}

The main symptom of selective mutism is that "the child shows consistent failure to speak in specific social situations in which there is an expectation for speaking (e.g., at school), despite speaking in other situations" (American Psychiatric Association, 2013). However, there are persons who not only do not speak but are also inhibited in expressing intent through nodding and eye or facial expressions and are slow in their behavior. On the other hand, there are also persons who can read aloud during class and converse with specific friends, the clinical images of

\footnotetext{
* Corresponding Author

Mailing Address: 4-4-37 Kofu, Yamanashi 400-8510, Japan

E-mail Address: hiroyukim@yamanashi.ac.jp

${ }^{\dagger}$ Formerly Faculty of Human Sciences, University of Tsukuba

Received February 7, 2019, Accepted June 20, 2020

DOI: 10.6033/specialeducation.9.23
}

which are various (Kawai \& Kawai, 1994).

Selective mutism is a relatively rare disorder. Its recorded prevalence rate is between $0.03 \%$ and $1 \%$ according to the Diagnostic and Statistical Manual of Mental Disorders (DSM-5) of the American Psychiatric Association, but frequent encounters in educational and clinical settings have also been pointed out (Yamamura, Uchiyama, Kato \& Sugiyama, 2014). Cho and Sonoyama (2018) reviewed 16 papers and found that the prevalence rate of selective mutism was $0.02 \%$ to $1.89 \%$. However, they point out that differences emerge depending upon the survey field and diagnostic criteria used. Matsushita, Okumura, Sakai, Shimoyama, and Sonoyama (2019) surveyed enrollment rates in Japanese schools and found that no major differences are seen in elementary and lower secondary school although children with selective mutism frequently appear in kindergarten $(0.66 \%)$, and the rate was $0.21 \%$ overall. In addition, in approximately 
$40 \%$ of all schools, children with selective mutism are enrolled or may be enrolled at all grade levels. Therefore, further study is required of the support given to children with selective mutism in all schools. Moreover, because it seems that there are major differences in educational content and activities in kindergarten, elementary school, and lower secondary school, it may be presumed that the difficulties faced by children with selective mutism and the support required differ depending upon the school type.

In case studies of support for children with selective mutism through coordination and cooperation with elementary school homeroom teachers, having children read aloud together in a group during classroom exercises, reading responses written on notes by the child seated next to them (Sonoyama, 2017), and giving communication cards with "Good morning," "Thank you," and other greetings written on them (Kojima \& Sekido, 2013) were considered depending on the homeroom. However, Okumura and Sonoyma (2018), based on a survey of adults who experienced selective mutism, point out that difficult circumstances in school are not limited to activities in which students read out loud, made presentations, sang, or otherwise had to use their voice. For example, difficult circumstances are varied, including inhibited behavior during physical education or arts and crafts, or isolation during events or break times. Furthermore, cases are also reported of selective mutism leading to bullying (Bunnel \& Beidel, 2013) and school refusal (Okumura \& Sonoyama, 2015; Rye \& Ullman, 1999) as secondary problems. Also, supporting children with selective mutism is difficult when difficulties do not arise in daily school life, which requires respectful understanding of the actual circumstances (Horie \& Kamata, 2016). Thus, although the difficulties faced by children with selective mutism and the necessity for support have been indicated, actual circumstances of difficulties and support have not been identified.

Selective mutism is considered an emotional disturbance under special needs education in Japan's education system. That is, in addition to support in regular classes, guidance for stabilizing emotions in a comfortable atmosphere is available as needed in resource rooms and special classes. The Ministry of Education, Culture, Sports, Science and Technology (MEXT) lists three aspects for schools to provide reasonable accommodation to children with disor- ders: "educational content and methodology," "support systems," and "facilities and equipment" (MEXT, 2014). Regarding children with selective mutism, it is believed that communication means and teaching materials for classes can be devised, and educational content can be modified and adjusted. In addition, establishing support systems with high levels of expertise, such as utilizing experts in emotional disturbance including doctors, and schools for special needs education, and encouraging the understanding of surrounding children, faculty, and parents, is being sought.

As stated above, the necessity of specific support systems has been indicated. However, previous studies have not identified the areas in which children with selective mutism face difficulties in schools in Japan and the support they are given. There is also a need to identify the degree of understanding faculty has of selective mutism and their consciousness of providing support to detect selective mutism at an early stage and offer support. Therefore, we conducted a survey among teachers working at schools for different tiers of education (kindergarten, elementary, and lower secondary school) to ascertain the teachers' views on the extent of the difficulties children with selective mutism face in school activities and their views on the in-school support the children require.

\section{Method}

\section{Target Schools}

This survey used 269 public schools within the jurisdiction of Southern Ibaraki Education Office. The breakdown of school types was 36 kindergartens (including three certified centers for early childhood education and care), 165 elementary schools, and 68 lower secondary schools. The population of the survey region was approximately $1,002,900$ people (as of November 1, 2017) in an area of approximately $1,514 \mathrm{~km}^{2}$.

Responses were received from 75 out of the 269 schools surveyed (a $27.9 \%$ response rate). The breakdown was 14 out of the 36 kindergartens (including zero certified center for early childhood education and care; $38.9 \%), 46$ out of the 165 elementary schools $(27.9 \%)$, and 15 out of the 68 lower secondary schools (22.1\%).

Furthermore, this survey was conducted simul- 
taneously with Matsushita et al. (2019), who conducted a questionnaire survey of enrollment rates among children with selective mutism using the same respondents and target schools. This study focused on children with selective mutism, and although 75 schools responded, we included analysis only from respondents who said that their school has such children-there were 31 such respondents.

\section{Survey Procedure}

The questionnaires were mailed to each school. They were enclosed with documents summarizing the study and requesting cooperation. Schools were asked, in the event that they consented, to have school principals sign consent forms, and representatives respond to the questionnaires, which were then placed in return envelopes to be mailed back. The survey was conducted from February to March 2017.

\section{Question Items}

The question items and responses to the study were as described below.

Difficulties in providing support. There were nine items concerning the difficulties of teachers in providing support to children with selective mutism in school. These included "Do not know the term 'selective mutism" and "Do not know symptoms of selective mutism." Responses were on a 4-point scale of " 0 : N/A" to "3: Applies."

Presence or absence of support systems. There were five items concerning whether certain school support systems for children with selective mutism were present or absent: (a) "information-sharing between teachers," (b) "specialized support by school counselors, etc.," (c) "resource room use," (d) "cooperation and adjustment by special needs education coordinators" and (e) "training workshops." The questions could be answered on a 2-point scale of presence or absence of each support system. MEXT (2018) defines "resource room" as the place where children with disabilities who are enrolled in and studying most of the time in regular classes may visit a few times a week to receive special instruction.

Support systems thought necessary for schools. The participants were free to response on what in-school support systems were thought necessary for children with selective mutism.

Settings indicating symptoms of selective mutism and degree of difficulty. Responses were given to the following questions on each child when child with selective mutism is enrolled.

(a) Difficulty engaging in schoolwork and activities: Kindergartens and elementary and lower secondary schools were asked to respond on a 4-point scale of "1: Not difficult" to "4: Very difficult" regarding nine subjects and 16 activities.

(b) Settings indicating symptoms of selective mutism: Responses were sought on 14 settings related to subjects and activities. Respondents could respond on a 2-point scale regarding which settings elicited "mutism," where students could not talk, and "freezing," where students not only could not talk but could also ceased activity. Furthermore, free responses were sought on other settings indicating symptoms.

(c) Details of support provided to children with selective mutism: Respondents could respond on a 2-point scale of whether 11 kinds of support had been provided for children with selective mutism, including "use of gestures" and "IC recorder use." The first and second authors discussed and carefully decided the question items referring to McHolm, Cunninghamm, and Vanier (2005), Kanmoku Net (2008), and the database of National Institute of Special Needs Education (2012). In particular, behavioral therapy such as exposure has been shown to be effective as an approach to anxiety disorders or selective mutism (Bergman, Gonzalez, Piacentini \& Keller, 2013; Vecchio \& Kearney, 2009), so the item "expert consultation" was used. Moreover, they were asked to respond on the effects of support that had been provided on a 4-point scale from "1: Not effective" to " 4 : Effective."

Furthermore, in this study, identification of whether subject children had selective mutism was not only limited to medical diagnosis but also included teacher judgments. Hence, following the objective of the survey and the ethical considerations at the top of the questionnaire, the following judgment criteria for selective mutism was included, referencing the DSM-5 diagnostic criteria.

"Selective mutism" asked about in this survey refers to inability to vocalize and speak in settings where there is an expectation of speaking, such as school, despite an ability to speak and understand words, as if there is a complete inability to speak at school despite normally speaking at home. This is also referred to as "elective mutism." 
In this survey, please provide responses for all students whom all of the following characteristics apply, regardless of medical diagnosis: cannot speak at school despite speaking at home; lack of speech that is not a result of slowed speech or lacking knowledge; symptoms lasting at least 1 month or longer, not just at the start of the school term; and symptoms are not a result of autism or mental illness.

\section{Analytical Method}

We scored "Difficulties in providing support" from "N/A" (0 points) to "Applies" (3 points), "Degree of difficulties in respective subjects and activities" from "Not difficult" (1 point) to "Very difficult" (4 points), and "Effects of providing support" from "Not effective" (1 point) to "Effective" (4 points), and then determined the median values for comparison. Furthermore, of the nine questions on "Difficulties in providing support," "Not recognized as problem needing support, as they can do many things despite not speaking" was a reversed question and was scored substituting 0 points for 3 points and 1 point for 2 points. In addition, regarding the presence or absence of support systems and mutism symptoms for which responses were sought on a 2-point scale, simple tabulation was performed per school type to determine the implementation rate and occurrence rate. This was computed by dividing the number that responded with the support provided or symptoms occurring by the total number of schools or the total number of cases surveyed. For the free responses, two of the authors (the second and fourth authors) segmented and coded the statements according to con- text. The authors then compared the codes generated and grouped them into superordinate conceptual categories.

\section{Ethical Considerations}

In conducting the survey, a summary of the study and protection of personal information were noted in the questionnaire, and responses were obtained after receiving the consent of the respondents. We obtained the approval of the Research Ethics Committee of the Faculty of Human Sciences at the University of Tsukuba.

\section{Results}

Of the 75 schools surveyed, 31 replied that they had children with selective mutism enrolled. The breakdown of the respondents' roles by education tier is shown in Table 1. Special needs education coordinators (SNECs), including SNECs who concurrently served as teachers in special classes (TSs), were the most numerous, representing $19(61.3 \%)$ of the 31 teachers. Of these 19 respondents, 16 worked at elementary schools and three worked at lower secondary schools (none worked at kindergartens). Next were "vice principal" and "class teacher," with each position representing four respondents (12.9\%). One respondent was TS who did not double as SNEC. This teacher and the six TSs who were doubling as SNECs represented $22.6 \%$ of the sample. All seven of these respondents worked at elementary schools.

Table 2 shows the results of "Difficulties in supporting children with selective mutism." As one of

Table 1 Occupation of the Respondents

\begin{tabular}{lcccc}
\hline & \multicolumn{3}{c}{ Type of school } & Total \\
\cline { 2 - 4 } & Kindergarten & Elementary & Lower secondary & $13(41.9 \%)$ \\
\hline Special needs education coordinator (SNEC) & 0 & 10 & 3 & $4(12.9 \%)$ \\
Vice principal & 0 & 1 & 3 & $4(12.9 \%)$ \\
Class teacher & 3 & 1 & 0 & $2(6.5 \%)$ \\
Head teacher in student guidance & 0 & 1 & 0 & $1(3.2 \%)$ \\
Principal & 1 & 0 & 0 & $1(3.2 \%)$ \\
Teacher in special class (TS) & 0 & 1 & 0 & $0(0.0 \%)$ \\
Curriculum coordinator & 0 & 0 & 0 & $6(19.4 \%)$ \\
TS doubling as SNEC & 0 & 6 & 7 & 31 \\
\hline Total & 4 & 20 & 0 \\
\hline
\end{tabular}

Note. TS=Teacher in special class; SNEC=special needs education coodinator. 
the respondents did not respond to all nine question items, the results obtain 30 of the 31 respondents. Four of the respondents worked at kindergartens, 19 at elementary schools, and seven at lower secondary schools. Among all the school types, "Not recognized as problem needing support as they can do many things despite not speaking" had the highest results, with a median value of 3.0 .

The overall median value (including all three tiers) for all other items was either 1.00 or less, indicating that these items were minimally problematic. However, among kindergarten teachers, the median was 2.00 for three of these items ("Do not know best way to achieve communication," "Do not know how to properly handle situations," and "Do not know how to get classmates to understand"), suggesting that these items were more problematic in kindergartens than the other two types of schools. Furthermore, the overall median value for "Do not know symptoms of selective mutism", "Do not know the term 'selective mutism," and "Cannot get family to understand need for support" was 0 (range: 0-3).

Table 3 shows the results for "Presence or absence of school support systems for children with selective mutism." Overall implementation rates were highest in order of "Information-sharing between teachers" (100.0\%), "Cooperation and adjustment by special needs education coordinators" (71.4\%), and "Specialized support by school counselors, etc." (44.8\%). On the other hand, "Resource room use" involving individual support was hardly provided, whatever the school type.

Table 4 shows the results of analyzing free responses to "School support systems thought necessary for selective mutism children." Nineteen of the 31 respondents provided responses here, and there were 42 responses in total. Responses were divided into four categories: [In-school cooperation] (21),

Table 2 Difficulties in Supporting Children with Selective Mutism (Median, Inter-quartile Range)

\begin{tabular}{lcccc}
\hline & $\begin{array}{c}\text { Kindergarten } \\
(n=4)\end{array}$ & $\begin{array}{c}\text { Elementary } \\
(n=19)\end{array}$ & $\begin{array}{c}\text { Lower secondary } \\
(n=7)\end{array}$ & $\begin{array}{c}\text { All } \\
(n=30)\end{array}$ \\
\hline $\begin{array}{l}\text { Not recognized as problem needing support as they can } \\
\text { do many things despite not speaking (reversed item) }\end{array}$ & $2.50(2.00-3.00)$ & $2.50(2.00-3.00)$ & $3.00(1.00-3.00)$ & $3.00(2.00-3.00)$ \\
Lack of understanding with family & $1.00(0.25-2.50)$ & $1.50(0.75-3.00)$ & $1.00(0.00-3.00)$ & $1.00(0.50-3.00)$ \\
Do not know best way to achieve communication & $2.00(1.00-3.00)$ & $1.00(1.00-2.00)$ & $1.00(1.00-1.00)$ & $1.00(1.00-2.00)$ \\
Do not know how to properly handle(since approach & $2.00(1.00-3.00)$ & $1.00(1.00-2.00)$ & $1.00(0.00-2.00)$ & $1.00(1.00-2.00)$ \\
$\quad$ thought to be good turns out to be unsuitable, etc.) & & & & \\
Do not know how to get classmates to understand & $2.00(0.50-2.00)$ & $1.00(0.75-2.00)$ & $1.00(0.00-1.00)$ & $1.00(0.00-2.00)$ \\
Do not understand difference from a shy personality & $1.00(0.25-1.75)$ & $0.50(0.00-2.00)$ & $0.00(0.00-1.00)$ & $1.00(0.00-1.50)$ \\
Do not know symptoms of selective mutism & $1.50(0.25-2.75)$ & $0.00(0.00-1.00)$ & $0.00(0.00-1.00)$ & $0.00(0.00-1.00)$ \\
Do not know the term "selective mutism" & $1.00(0.25-2.50)$ & $0.00(0.00-1.00)$ & $0.00(0.00-1.00)$ & $0.00(0.00-1.00)$ \\
Cannot get family to understand need for support & $0.00(0.00-1.50)$ & $0.50(0.00-1.00)$ & $1.00(0.00-2.00)$ & $0.00(0.00-1.50)$ \\
\hline
\end{tabular}

Note. Values in parentheses are inter-quartile range. 0: N/A, 1: Somewhat N/A, 2: Somewhat applies, 3: Applies.

Table 3 Number of Schools with Support Systems for Children with Selective Mutism

\begin{tabular}{lcccc}
\hline & $\begin{array}{c}\text { Kindergarten } \\
(n=4)\end{array}$ & $\begin{array}{c}\text { Elementary } \\
(n=19)\end{array}$ & $\begin{array}{c}\text { Lower secondary } \\
(n=7)\end{array}$ & $\begin{array}{c}\text { All } \\
n=30\end{array}$ \\
\hline Has some support system & $4(100.0)$ & $19(100.0)$ & $7(100.0)$ & $30(100.0)$ \\
\hline $\begin{array}{l}\text { Information-sharing between teachers } \\
\text { Cooperation and adjustment by special needs education }\end{array}$ & $\begin{array}{l}2(100.0) \\
\quad \text { coordinators }\end{array}$ & $19(100.0)$ & $7(100.0)$ & $30(100.0)$ \\
$\begin{array}{l}\text { Specialized support by school counselors, etc. } \\
\text { Training workshops }\end{array}$ & $2(50.0)$ & $12(63.2)$ & $6(85.7)$ & $20(66.7)$ \\
Resource room use & $0(0.0)$ & $5(26.3)$ & $2(28.6)$ & $13(43.3)$ \\
\hline
\end{tabular}

Note. Values in parentheses are \%. 
Table 4 School Support Systems Thought Necessary for Children with Selective Mutism $(n=19)$

\begin{tabular}{|c|c|c|}
\hline Category & Sub-category & Specific example \\
\hline \multirow{5}{*}{$\begin{array}{l}\text { In-school } \\
\text { cooperation }(21)\end{array}$} & - Promotion of common understanding (11) & - Promoting common understanding among teachers \\
\hline & •Support team $(5)$ & -Developing a shool-wide support system/support team \\
\hline & •Information sharing (3) & • Sharing information among teachers \\
\hline & - Holding case conferences (1) & - Holding case conferences regularly \\
\hline & - Understanding the circumstances (1) & - Understanding the circumstances of children \\
\hline \multirow[t]{2}{*}{$\begin{array}{l}\text { Professional } \\
\quad \text { improvement (12) }\end{array}$} & - Organaizing training workshops (7) & $\begin{array}{l}\text { - Training workshops for proper understanding and } \\
\text { knowing appropriate approaches }\end{array}$ \\
\hline & •Cooperation with outside special agencies (5) & $\begin{array}{l}\text {-Expert guidance and advice from universities, medical } \\
\text { institutions, etc. }\end{array}$ \\
\hline \multirow[t]{2}{*}{$\begin{array}{l}\text { Support environment } \\
\text { creation (5) }\end{array}$} & - Physical environment creation (3) & $\begin{array}{l}\text {-Secure place for small groups to casually spend time, } \\
\text { and use special classes and nurse's office }\end{array}$ \\
\hline & -Human environment creation (2) & $\begin{array}{l}\text { - Use of counseling or consultation by school counselors } \\
\text { or other experts }\end{array}$ \\
\hline \multirow[t]{2}{*}{$\begin{array}{l}\text { Cooperation with } \\
\text { parents }(4)\end{array}$} & - Parent-teacher conference (2) & $\begin{array}{l}\text { - Developing a consultation system for family to tell how } \\
\text { the child is at home and ask s/he is at school }\end{array}$ \\
\hline & - Parent's understanding to support their child (2) & - Building trust with parents and asking for cooeration \\
\hline
\end{tabular}

Note. Multiple responses. Values in parentheses are the number of responses.

Table 5 Difficulties in Respective Subjects and Activities (Median, Inter-quartile Range)

\begin{tabular}{lllll}
\hline & $\begin{array}{c}\text { Kindergarten } \\
(n=6)\end{array}$ & & $\begin{array}{c}\text { Elementary } \\
(n=27)\end{array}$ & $\begin{array}{c}\text { Lower secondary } \\
(n=9)\end{array}$ \\
\hline Circle time & $1.00(1.00-1.50)$ & Morning and afterschool meetings & $2.00(1.00-3.00)$ & $2.00(1.00-3.50)$ \\
lunch & $1.00(1.00-2.00)$ & lunch & $1.00(1.00-2.00)$ & $2.00(1.00-3.50)$ \\
Free play & $1.50(1.00-2.00)$ & Break time & $1.00(1.00-2.00)$ & $2.00(1.00-3.00)$ \\
Exercise & $1.00(1.00-1.25)$ & Japanese language & $2.00(2.00-4.00)$ & $3.00(2.00-4.00)$ \\
Music & $1.50(1.00-2.25)$ & Social studies & $2.00(1.00-3.50)$ & $3.00(2.00-4.00)$ \\
Art and craft & $1.00(1.00-1.50)$ & Math & $2.00(2.00-3.00)$ & $3.00(2.00-4.00)$ \\
Shared storytelling & $1.00(1.00-2.25)$ & Science & $2.00(1.00-3.00)$ & $3.00(2.50-4.00)$ \\
FInger play, etc. & $1.00(1.00-1.00)$ & Living environment studies & $2.50(1.00-3.00)$ & $3.50(2.25-4.00)$ \\
Group play & $2.50(1.00-3.25)$ & Physical education & $2.00(1.00-3.00)$ & $3.00(1.50-4.00)$ \\
& & Art and craft & $1.50(1.00-2.25)$ & $2.00(1.50-4.00)$ \\
& & Foreign language & $2.00(1.00-4.00)$ & $3.00(2.00-4.00)$ \\
& & Home economics & $1.50(1.00-2.75)$ & $4.00(1.50-4.00)$ \\
& & Music & $2.00(2.00-4.00)$ & $4.00(3.00-4.00)$ \\
& & Morals & $2.00(1.00-3.00)$ & $4.00(2.00-4.00)$ \\
& & the Period for integrated studies & $2.00(1.00-3.00)$ & $3.00(1.50-3.50)$ \\
& & Special activities & $2.00(1.00-3.00)$ & $3.00(2.00-3.00)$ \\
\hline
\end{tabular}

Note. Values in parentheses are inter-quartile range. 1: Not difficult, 2: Somewhat difficult, 3: Difficult, 4: Very difficult.

[Professional improvement] (12), [Support environment creation] (5), and [Cooperation with parents] (4). Responses requiring [In-school cooperation] and [Professional improvement] were particularly numerous. Guidance and advice by outside special agen- cies, such as universities and medical institutions and workshops, were indicated as necessary.

The results for "Difficulty engaging in schoolwork and activities" are shown in Table 5. These responses pertained to a total of 42 children identified with 
selective mutism. Of these children, six were in kindergartens, 27 in elementary schools, and nine in lower secondary schools. In kindergartens, the degree of difficulty engaging in "Group play" was high at 2.5. This was followed by high difficulty in "Music" and "Free play" activities (1.5) and low difficulty in activities without vocalization, such as "Finger play" and "Exercise" (1.0). In elementary and lower secondary schools, the degree of difficulty covered a broad range from 1 to 4 , with significant differences seen depending upon the child. In elementary schools, difficulty was highest in "Living environment studies" (2.5) and lowest in non-class activities such as "Break time" and "Lunch." Difficulty was relatively low in "Arts and crafts" and "Home economics" (1.5) in each subject. On the other hand, in lower secondary schools, difficulty was highest in "Home economics," "Music," and "Morals" (4.0). Similar to elementary schools, difficulty was relatively low during "Break time" and "Lunch" (2.0), but high overall.

The results of "Settings indicating selective mutism symptoms" are shown in Table 6. Mutism symptoms manifested the most when teachers asked questions in both elementary and lower secondary schools, with occurrence rates of $92.6 \%$ and $100 \%$, respectively. In elementary schools in particular, "freezing" symptoms were also seen at a rate of $37.0 \%$. In addition, in lower secondary schools, the occurrence rate was high overall regardless of the setting, but in elementary schools, a tendency for mutism and "freezing" symptoms to appear was seen when students were reading aloud in class, making presentations, being greeted by friends, and engaging group activities. Furthermore, in elementary and lower secondary schools, the occurrence rate of mutism symptoms at break time was relatively low: $63.0 \%$ and $77.8 \%$, respectively. However, the occurrence rate was highest during break times (66.7\%) in kindergartens, similar to when taking the lead or giving orders in morning meetings.

The results of "Details of support for children with selective mutism and their effects" are shown in Table 7. Overall, "Consideration of group formation" (78.6), "Consideration of seating" (76.2\%), and "Encouraging understanding of classmates" (66.7\%) were likely to be provided, with high efficacy score of 3.0 (median value). The highest effects were for "Use of resource room" (4.0), but the num-

Table 6 Number of Cases Per Settings Indicating Selective Mutism Symptoms

\begin{tabular}{|c|c|c|c|c|c|c|}
\hline & \multicolumn{2}{|c|}{ Kindergarten $(n=6)$} & \multicolumn{2}{|c|}{ Elementary $(n=27)$} & \multicolumn{2}{|c|}{ Lower secondary $(n=9)$} \\
\hline & Mutism & "Freezing" & Mutism & "Freezing" & Mutism & "Freezing" \\
\hline \multicolumn{7}{|l|}{ [In each subject or activity] } \\
\hline Reading aloud of textbooks and summaries & & & $23(85.2)$ & $5(18.5)$ & $8(88.9)$ & $1(11.1)$ \\
\hline Presentation of writings and impressions & & & $22(81.5)$ & $10(37.0)$ & $8(88.9)$ & $1(11.1)$ \\
\hline Responses to teacher questions & $2(33.3)$ & $1(16.7)$ & $25(92.6)$ & $10(37.0)$ & $9(100.0)$ & $0(0.0)$ \\
\hline Small group conversation activities & $2(33.3)$ & $1(16.7)$ & $22(81.5)$ & $3(11.1)$ & $8(88.9)$ & $0(0.0)$ \\
\hline $\begin{array}{l}\text { Individual skill demonstrations_-solo presentations, } \\
\text { performances, etc. }\end{array}$ & $0(0.0)$ & $0(0.0)$ & $21(77.8)$ & $7(25.9)$ & $8(88.9)$ & $1(11.1)$ \\
\hline $\begin{array}{l}\text { Presentation of group skills-chorus, ensemble, team } \\
\text { play, etc. }\end{array}$ & $1(16.7)$ & $1(16.7)$ & $21(77.8)$ & $5(18.5)$ & $8(88.9)$ & $1(11.1)$ \\
\hline \multicolumn{7}{|l|}{ [Daily extracurricular activities] } \\
\hline Teacher and friend greeting situations & $3(50.0)$ & $1(16.7)$ & $22(81.5)$ & $2(7.4)$ & $8(88.9)$ & $0(0.0)$ \\
\hline Morning classroom roll call & $3(50.0)$ & $1(16.7)$ & $16(59.3)$ & $1(3.7)$ & $8(88.9)$ & $0(0.0)$ \\
\hline Leading morning meetings, etc. & $4(66.7)$ & $2(33.3)$ & $20(74.1)$ & $3(11.1)$ & $9(100.0)$ & $0(0.0)$ \\
\hline Break time & $4(66.7)$ & $1(16.7)$ & $17(63.0)$ & $3(11.1)$ & $7(77.8)$ & $2(22.2)$ \\
\hline Club activities & & & $11(40.7)$ & $0(0.0)$ & $8(88.9)$ & $0(0.0)$ \\
\hline \multicolumn{7}{|l|}{ [Activities in school events] } \\
\hline Sports days & $3(50.0)$ & $1(16.7)$ & $21(77.8)$ & $3(11.1)$ & $8(88.9)$ & $0(0.0)$ \\
\hline Field trips, school excursions, etc. & $2(33.3)$ & $0(0.0)$ & $21(77.8)$ & $0(0.0)$ & $8(88.9)$ & $0(0.0)$ \\
\hline Choral competition, recitals, cultural festivals, etc. & $2(33.3)$ & $1(16.7)$ & $19(70.4)$ & $2(7.4)$ & $8(88.9)$ & $0(0.0)$ \\
\hline
\end{tabular}

Note. Multiple responses. Values in parentheses are \%. 


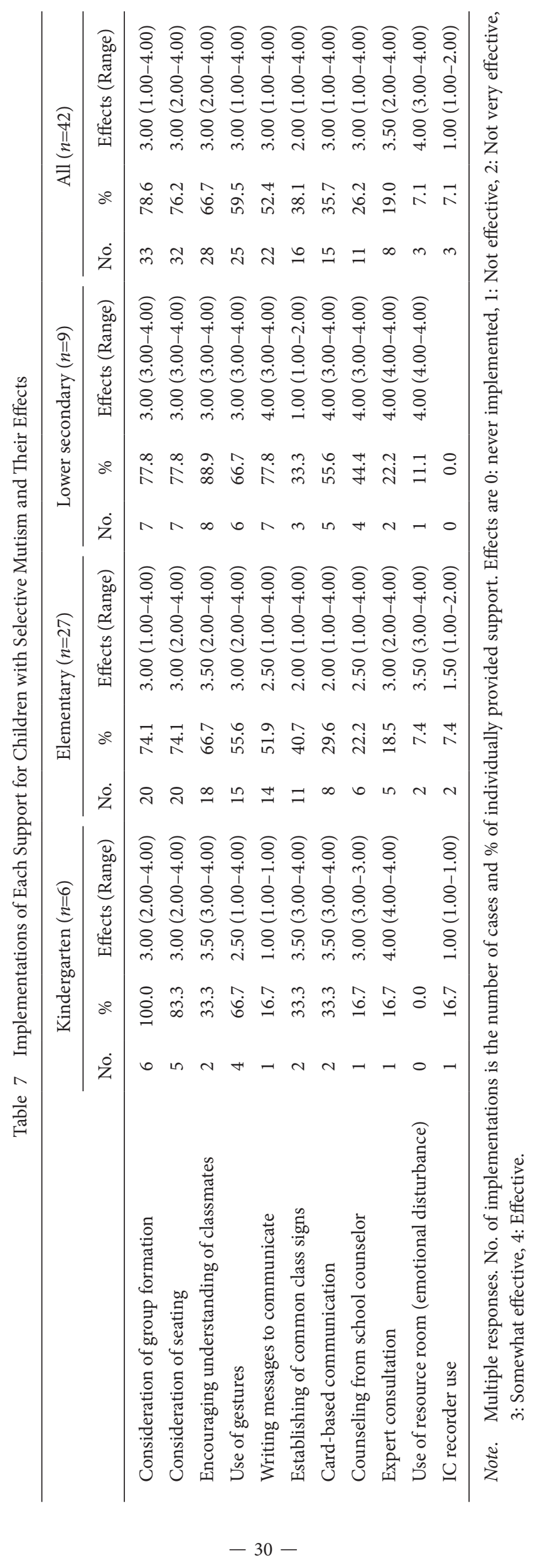


ber of implementation cases was only three (7.1\%). Similarly, "Expert consultation" was relatively rare, at $19.0 \%$, but it had a relatively high efficacy score of 3.50. On the other hand, the lowest effects were for "Use of IC recorder" (1.0), and the number of implementation cases was three (7.1\%). Among kindergartens, "Consideration of group formation" and "Consideration of seating" were very frequent, at $100 \%$ and $83.3 \%$, respectively, whereas "Encouraging understanding of classmates" (33.3\%) and "Writing messages to communicate" (16.7\%) were rarer by comparison. The latter two measures were more frequent among elementary schools, at $66.7 \%$ and $51.9 \%$, respectively, and even more frequent among lower secondary schools, at $88.9 \%$ and $77.8 \%$, respectively. Of the two items, "Writing messages to communicate" had an efficacy score of 4.0 among lower secondary schools. "Establishing common class signs" was rare on the whole, at $38.1 \%$. This measure had an efficacy score of 3.5 among kindergartens, but the equivalent score among the elementary and lower secondary schools was lower, at 2.0 and 1.0, respectively.

\section{Discussion}

In this study, we conducted a questionnaire survey of kindergartens, elementary schools, and lower secondary schools to ascertain the teachers' views on the extent of the difficulties children with selective mutism face in-school activities and their views on the in-school support the children require. Due to the poor response rate overall, and due to the low rate of respondents who had children with selective mutism at their school, the sample was too small and biased to allow us to extrapolate the findings. Accordingly, this discussion will be limited in scope.

The teachers recognized that students with selective mutism required support according to the results, and they perceived no major problems in providing such support. However, we found that although understanding of selective mutism was advancing to some degree, there tended to be a lack of understanding of how to handle it according to individual educational needs. This is similar to the results of Horie and Kamata (2016). It is not only important for teachers to have a general knowledge of selective mutism symptoms but also to study specific support methods matching the individual edu- cational needs of children. The results revealed that communication is a particular problem among kindergartens. Many attempts were made to use gestures in kindergartens as a form of actually providing support, and responses were that it was not so effective. It is believed that the higher the grade, the more characters and signs students can remember and effectively use, and thus establishing means of communication, and reducing difficulties. Moreover, implementations indicate that it is effective although getting classmates to understand is indicated as difficult. The responses on difficulties when providing these forms of support were widely distributed from 0 to 3 points, and there appeared to be differences in teacher support skills. In future, there will be a demand to raise the level of knowledge and skills for supporting children with selective mutism, including the development of programs to promote their classmates' understanding.

Schools conducting training workshops on selective mutism are few; in fact, there is not one kindergarten school. One definite issue for the future is more teachers acquiring the knowledge and skills to support children with selective mutism through training workshops. Information sharing between teachers has been widely implemented as a support system in schools, using mainly SNECs. From the free response answers, coordinated support inside and outside schools is required. Greater use of SNECs will be sought in future. Most of the respondents to this study were SNECs, but they hold the post concurrently with other positions. SNECs are appointed in almost all elementary and lower secondary schools. However, very few are full time (Miyaki, 2015), and thus, environments definitely need to be established with multiple full-time special needs educations coordinators to support children with selective mutism enrolled in many schools.

Many of the schools surveyed enlisted a school counselor or similar professional to assist children with selective mutism, but the use of such professionals was somewhat low among elementary schools. If elementary schools are enlisting school counselors infrequently, it is not because they lack such counselors. According to a 2017 MEXT survey, counselors were employed by $70.7 \%$ of elementary schools and $94.5 \%$ of lower secondary schools (MEXT, 2017) besides some regional variation. Likewise, we found that counselors were employed by $16(84.2 \%)$ of the 
elementary schools and by all seven of the lower secondary schools. Although the sampling issues prevent us from generalizing the results, the above data might imply that schools could do more to involve their school counselors in efforts to support children with selective mutism and to prevent issues from arising. That said, the effects in cases in which support was provided are shown to be high in lower secondary schools. MEXT will be placing school counselors at public elementary and lower secondary schools throughout the country from 2019. However, the fact that effects were not high for school counselors in elementary schools indicates that assigning them to all schools will not manifest direct effects based on the results of this study. McHolm et al. (2005), as well as Sonoyama (2017), point out that support for children with selective mutism should be based upon behavioral therapy, including stimulus fading and exposure. Effective methods are those that take a systematic approach through the collaboration of schools, homes, and experts. This means that a topic of discussion regards how to increase the number of school counselors with appropriately high levels of expertise in areas such as coordinating cooperation between relevant parties, as well as behavioral therapy.

What the difficulties faced by children with selective mutism have in common is that they occur during activities and settings requiring speech. For example, mutism symptoms are likely to manifest with a strong degree of difficulty when singing, reading aloud, or making presentations. On the other hand, the degree of difficulty is less during free time (e.g., lunch and break time). However, in kindergartens, difficulty was high during break time such as group play or free play settings, which was different from elementary and lower secondary schools. This is probably because there are various anxiety-producing stimuli during break time in kindergartens. Children are sometimes asked to sing a song or say a line of dialog in group play, and they often have unexpected contacts with unspecified classmates in free play. Moreover, break time in kindergartens, similar to free play, may be affected by noisy environments, such as children speaking in loud voices or running around. Due to the difference in learning environment, the difficulties observed in kindergartens are different from those observed in elementary or lower secondary schools. Thus, the support required may be pro- viding a place where children with selective mutism can feel comfortable, especially in kindergartens.

Our findings suggest that the teachers who provide support require a better collaborative framework inside and outside the school and more specialist expertise. Specific ways to improve specialization include holding training workshops, as well as advice and consultation from experts at universities and medical institutions. At present, we found that hardly any training workshops are being held, suggesting that support through the use of resource rooms and school counselors is inadequate. In addition, there are individual differences regarding the difficulties faced by children with selective mutism. This means that the elements acting as anxiety-evoking stimuli vary depending upon the individual. Consequently, it is believed that constructing effective environments and establishing support methods for children with selective mutism is difficult, and forms of support need to be studied while verifying individual responses. Based on these circumstances, it appears that the establishment of specialized support systems is not catching on. When children with selective mutism are not enrolled in school, it is difficult to make any headway in establishing support systems. However, according to Matsushita et al. (2019), children with selective mutism are enrolled in approximately $40 \%$ of schools. Therefore, every school should be aware of the possibility that children with selective mutism are enrolled in. Furthermore, it is highly important to gather information of difficult situations and effective support strategies for those children as well as to establish a school system which each teacher can easily access to the information when they need. In future, there will be a demand for the construction of support systems incorporating a preventive perspective, regardless of any enrollment.

This study is limited to the areas below, and therefore, there remain topics for future discussion. First, as this was a survey study using a questionnaire, we were not able to fully investigate all the specific details of support provided at each school. Because close-ended questions were used to collect information on the support system in school, it remains unclear how much support they were providing or how they evaluated whether the support was effective. As respondents' subjectivity was not fully controlled, it was difficult to have a further discussion. It may be possible to collect detailed information 
on the methods and extent of information sharing through interviews and thus study support systems that are more effective. In addition, the number of sample responses was small; hence, there are significant biases between the school types. In particular, the number of cases of selective mutism was low in kindergartens and lower secondary schools. Hence, this study could not analyze symptoms including "freezing." Another issue concerns the fact that we neglected to specify the type of person who should respond to the survey. The respondents represent an odd mixture of roles as a result of this omission. Some of the respondents may have had a poor grasp of the circumstances of children with selective mutism. A future study should limit the sample to SNECs or an equivalent thereof. The number of cases was another issue; because there was a small number of cases, a statistical study was not possible, and it was difficult to generalize the findings. A future study will require a larger survey scope in order to analyze a larger number of samples.

In future, schools in Japan will also need to provide reasonable accommodation for children with selective mutism. The reasonable accommodations indicated by MEXT, which include the construction of support systems such as non-verbal expression methods (i.e., gestures and writing messages to communicate), adjustments to environments, and engagement for understanding, are also highlighted as necessary and effective in this study. There is also a need to further study forms of support to prevent secondary disorders in children with selective mutism and to allow them to more easily spend time at school.

\section{Acknowledgments}

This work was supported by JSPS KAKENHI Grant Number 16H03808. We would like to thank Editage (www.editage.jp) and Dr. Kumi Sato for English language editing.

\section{References}

American Psychiatric Association (2013) Diagnostic and statistical manual of mental disorders, 5th edition. Author, Washington, DC.

Bergman, R. L., Gonzalez, A., Piacentini, J., \& Keller, M. L. (2013) Integrated behavior therapy for selective mutism: A randomized controlled pilot study. Behaviour Research and Therapy,
$51,680-689$.

Bunnell, B. E. \& Beiclel, D. C. (2013) Incorporating technology into the treatment of a 17-year-old female with selective mutism. Clinical Case Studies, 12, 291-306.

Cho, S. \& Sonoyama, S. (2018) A brief review of the literature on the prevalence of selective mutism. Japanese Journal of Disability Sciences, 42, 227-236. (in Japanese)

Horie, K. \& Kamata, H. (2016) Questionnaire study of the primary school teachers' level of the understanding of the selective mutism and the attitudes about the support for the children of selective mutism Monami: The Comparison of the answers of primary school teachers and the junior college students in the teacher-training course. Bulletin of Kyushu Women's University, 52, 77-91. (in Japanese)

Kanmoku Net (2008) What is selective mutism? Gakuensha, Tokyo. (in Japanese)

Kawai, Y. \& Kawai, E. (1994) Psychology and guidance for children with selective mutism; the cooperation between teachers and parents. Taken Publishing, Tokyo. (in Japanese)

Kojima, T. \& Sekido, H. (2013) Using communication cards to teach greetings to an elementary school pupil with selective mutism. Japanese Journal of Special Education, 51, 359-368. (in Japanese)

Matsushita, H., Okumura, M., Sakai, T., Shimoyama, M., \& Sonoyama, S. (2019) A study on the enrollment rate of children with selective mutism in kindergarten, elementary school, and lower secondary school in Japan. Journal of Special Education Research, 8, 11-19.

McHolm, A. E., Cunningham, C. E., \& Vanier, M. K. (2005) Helping your child with selective mutism. New Harbinger Publications, Oakland.

Ministry of Education Culture, Sports, Science and Technology (2012) Report of the Working Group for Examining Reasonable Accommodations. Special Needs Education Division, Elementary and Secondary Education Bureau. (in Japanese) http:// www.mext.go.jp/b_menu/shingi/chukyo/chukyo3/046/ houkoku/1316181.htm (Retrieved August 30, 2019)

Ministry of Education Culture, Sports, Science and Technology (2017) School health examination survey 2016. Analytical Research Planning Division, Education Policy Bureau. (in Japanese) http://www.mext.go.jp/b_menu/toukei/chousa05/ hoken/1268826.htm (Retrieved September 6, 2019)

Ministry of Education Culture, Sports, Science and Technology (2018) Special needs education. Special Needs Education Division, Elementary and Secondary Education Bureau. November 9, 2018. https://www.mext.go.jp/en/policy/education/elsec/ title02/detail02/1373858.htm (Retrieved March 6, 2020)

Miyaki, H. (2015) Needs of special needs education coordinators at regular school. Bulletin of Yamaguchi Gakugei University, 6, 
67-75. (in Japanese)

National Institute of Special Needs Education (2014) Database for supporting development of inclusive education system. (in Japanese) http://inclusive.nise.go.jp/ (Retrieved March 26, 2020)

Okumura, M. \& Sonoyama, S. (2015) Voice volume feedback and in vivo exposure intervention for a high school student with selective mutism. Journal of Special Education Research, 3, 5564.

Okumura, M. \& Sonoyama, S. (2018) A study on the difficulties in school life faced by students with selective mutism and support from teachers and classmates: A survey of people with a history of selective mutism. Japanese Journal of Disability Sciences, 42, 91-103. (in Japanese)
Rye, M. S. \& Ullman, D. (1999) The successful treatment of longterm selective mutism: A case study. Journal of Behavior Therapy and Experimental Psychiatry, 30, 313-323.

Sonoyama, S. (2017) Consultation with the teacher, mother, and special education coordinator of an elementary school student with selective mutism: A case study. Japanese Journal of Disability Sciences, 41, 195-208. (in Japanese)

Vecchio, J. \& Kearney, C. A. (2009) Treating youths with selective mutism with an alternating design of exposure-based practice and contingency management. Behavior Therapy, 40, 380-392.

Yamamura, J., Uchiyama. M., Kato, D., \& Sugiyama, T. (2014) Treatment for selective mutism. Sodachi no kagaku, 22, 63-67. (in Japanese) 